$\mathrm{Oz}$

Volume 15

Article 7

$1-1-1993$

\title{
The Grit and Grist of Thinking...
}

Ben Nicholson

Follow this and additional works at: https://newprairiepress.org/oz

Part of the Architecture Commons

(c) (1) $(9$

This work is licensed under a Creative Commons Attribution-Noncommercial-No Derivative Works 4.0 License.

\section{Recommended Citation}

Nicholson, Ben (1993) "The Grit and Grist of Thinking...," Oz: Vol. 15. https://doi.org/10.4148/

2378-5853.1246

This Article is brought to you for free and open access by New Prairie Press. It has been accepted for inclusion in Oz by an authorized administrator of New Prairie Press. For more information, please contact cads@k-state.edu. 
Ben Nicholson

\section{Wandering}

Leaves. It was a weekend of trees in October. There are so many trees in Pennsylvania that they appear to have run amok. The trees are shedding leaves to such an extent that they have gone out of control. Wherever you go, there are trillions of leaves; they are a plague, nobody knows what to do with them and they cover the entire cityscape making an indescribable mess. Wherever you go, every horizontal or near horizontal surface is covered with them. When the leaves sprouted and turned green in the spring it seemed that all was going so well, but something went awry. Now the city has to dispose of the flaked deadness, for it has become a blight to every dwelling. It does not seem to be a problem in the forest for somehow it becomes assimilated and soaked up in the ground. It is remarkable that almost every leaf in the city is removed each year. Every single leaf is touched with a rake and collected, packed and pushed down into plastic bags and carted off to the city dump where they asphyxiate under plastic sheeting and die a second time in ignoble anonymity.

Art galleries. In big exhibitions it is illegal to draw whilst looking at a work of art. What happens if you look away

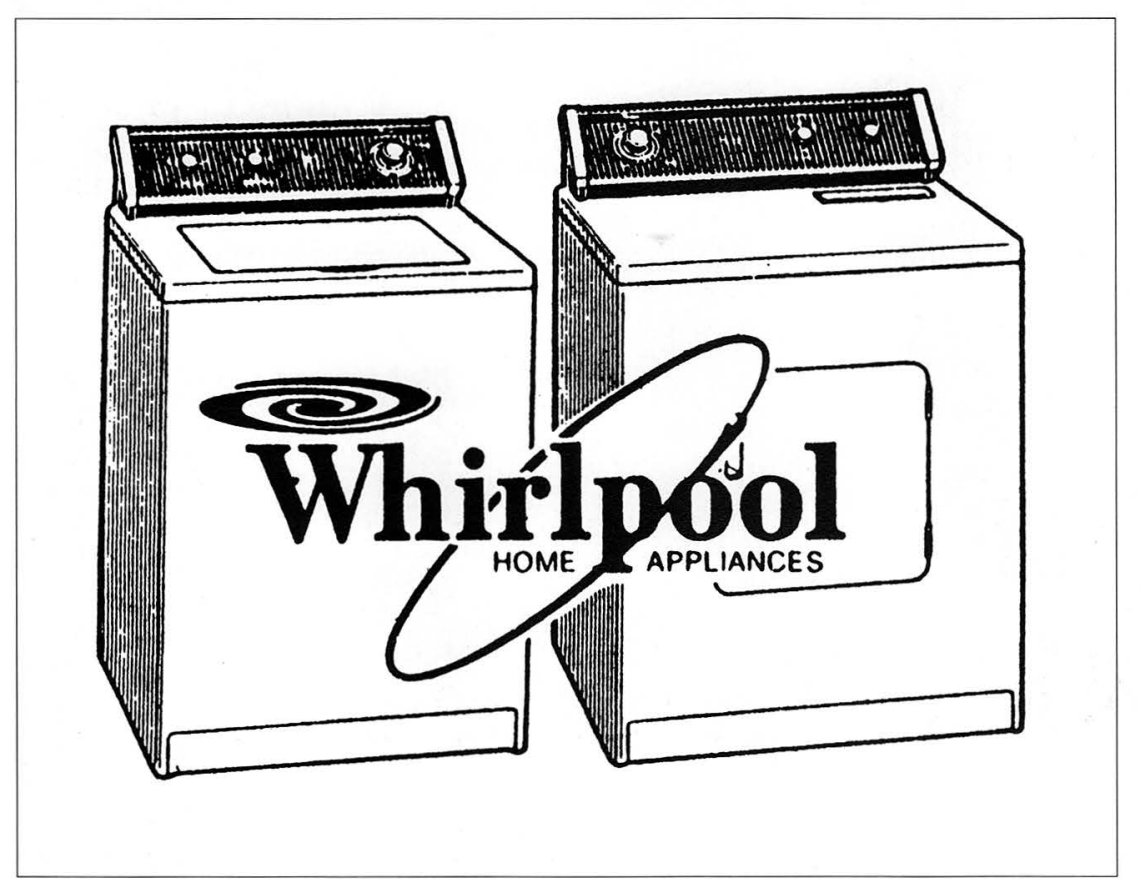

from a painting and then draw? Is it illegal to stare at the painting for five minutes and then walk away and draw in another room? The memory sits somewhere in this filthy little institutional equation.

Small town life. When the bell rings each Sunday everyone is summoned to the building, regardless of standing. In principle, every one enters the building to act goodly and Godly; each person comes to listen to wisdom and to make separate peace. In the congregation there is a banker who has been receiving disenfranchised residents in town who apply to him for loans which he readily gives out. When he gives a loan, he knows that often a recipient's situation is hopeless and it is only a matter of time before the assets do change hands and the banker, disenfranchised, and the sage are once again beneath the Sunday bell. All three are fully aware of what has taken place. The sage now has the chance to speak out against the banker for his premeditated cruelty, to the disenfranchised for their inability to act prior to the events that led to crisis, and to the township for allowing such a blatant activity to take place in their midst. What can the sage do? If he speaks against the disenfranchised they would only respond that the system is preordained and that their gate was sealed from the outset. If he speaks against the banker he may feel the pinch by the withdrawal of funds donated to the building. If he speaks against the township they will wonder about their own values and those of the sage.

To come to terms with the matter he can: 1) Speak out with absolute candor about all aspects of the matter.

2) Refer to a text that exemplifies the situation.

3) Wait for the time to pass to allow the matter to be swallowed up amongst other issues.

4) Form an argument that makes the aggressor the defendant.

5) Allow written laws to adjudicate the matter.

6) Resign, forming a principle as close to personal sacrifice as one can get, and thereby give future generations guidance through martyrdom.

7) Arrange to pay off the disenfranchised even though they know they are still right but prefer the questionable ethics of the situation to remain the same as long as they have material goods.

8) Engage blackmail, or threaten the parties involved.

9) Perform magic, administer maleficent drugs or resolve the issue through murder (naughty!).

Day to day life is composed of matters such as this, all of them an uneven mat that holds together because its mass of directions and counter-directions keep it in stasis.

Yellow Pencils. Most people feel sorry for something within their sphere of influence. Toilet paper has a sorry lot in life but it is not really enough of a thing to 
help its cause. Plastic bottles have a hard life because they have so much potential for repeated use, yet they never get the chance of fulfillment. Pencils on the other hand, are always worth helping out. A pencil in the wrong hands can have a sad life; its owner might constantly sharpen it and consequently only skinny little cylinders of graphite would get used, the bulk of the material being ground into dust before it even got the chance to prove its self worth. A pencil is loaded with so much potential that it is a crime to have it do anything but that which its owner is best capable of. Once I found an " $\mathrm{H}$ " pencil abandoned on the floor of the Rice School of Architecture. It was nearly "full" and so it was unlikely that it had had much of a start in life. I retrained the pencil and it served me well. During the first stage of its orphan life, it was sharpened by hand in the normal manner, but once it had become too short to hold, it entered its second phase, being used in conjunction with an aluminum penci holder. After it had been sharpened up to the holder's lip, it was removed and one of two things could have happened to it. Classically, the wood would be burned off and the half inch lead used in the compass, but this pencil stub was labeled with a tag describing what it had accomplished and then put into a box for safe keeping. My favorite yellow pencils are the half pencils found in libraries, used only a few times before they are so short, the "handles" of library pencils are confused with the usable graphite within them. These pen- cils are so grateful for being rescued from the hands of people who are too flaky to have remembered to bring their own writing instrument to the library.

Dog Poo. What is it, in this absurd culture of ours, that permits a healthy, mature, wealthy woman, such as the one outside my window, to stand beside a dog whilst it shits? Why would she then stoop down and actually pick up the lukewarm poo in her hand with only a plastic sandwich bag between her skin and it? The bag of shit then goes into the pocket of her fur coat. Is this weird or are we collectively undergoing a decay of sensible standard?

\section{Domesticity}

Mowing the Lawn. In the garden there are always millions of tasks to do each day. For example, when considered in slow motion, it becomes apparent that grass is cut one blade after another in excruciating sequence by the lawn mower. It is the single scything action of the flying blades that blurs the articulate itty-bitty job into a single continuum, whilst at the same time containing our sanity.

Orange Juice. To make a small amount of juice, that has the correct 3:1 proportion of concentrate to water, scoop out part of the frozen juice and replace that vacancy with water three times, allowing the remaining juice to form the bottom of the can. Of course, this can be done only once.
Bills. The number across my phone bill is 013120883190540404012500910 1200325700000342100000755918 .

Even if I were to change one number "for the sake of security," Illinois Bell would undoubtedly know which one had been changed.

\section{Abstracts}

Shadows. With the addition of each light bulb, objects are supposed to be seen more clearly, however each light bulb brings an unseen extra shadow. Objects in museums are lit by many spotlights that form a multiple reiteration of the object, resulting in the cast shadows camouflaging the object through their intersections. In this age of multiple light sources, a single shadow is rare; we now have to carry a baggage of multi-shadows around with us permanently.

Consumerism. Why are Americans referred to as consumers more readily than being called humans? Begin a campaign to erode this preference.

Armpits. Which part of the armpit delivers the smell? Is it the convex shape belonging to the arm? Does the hairy concavity wrongly get blamed for the smell? Perhaps the armpit is a misnomer because the smelly convexity fits into the pit's concavity.

Machinery. There is something about machinery that is perplexing: on a particular day someone decides that a ma- chine is no longer to be used. Tires are subject to this quality: one day they run along at fifty-five MPH and on the next they are considered dangerous, yet the tire is no different from the end of one day to the start of the next.

Impossibilities. Music has been written that is impossible to play. Literature has been written that is impossible to read. Architectural drawings have been made that are impossible to build. Will is all that is left that can puncture these impossibilities.

\section{Immolation}

Pages. I have never trusted turning over a loose page of text, because I like to see the words of the page I have just read. But, if I do this, the order of the pile of pages become reversed. I prefer to witness the pile in a reverse order of pagination and see the printed words on the last page than to not see the words and have the pages in the right order.

Method. I am suspicious of my method, of how work is laid out. I recognize the need for a switching back and forth between what is possible in construction and what I desire. The more I know about making, the less inclined I am to do things through drawing alone. I will look for a way to do things with materials that I can improve upon in thought, but first I need to know what my method will be (and vice versa). 


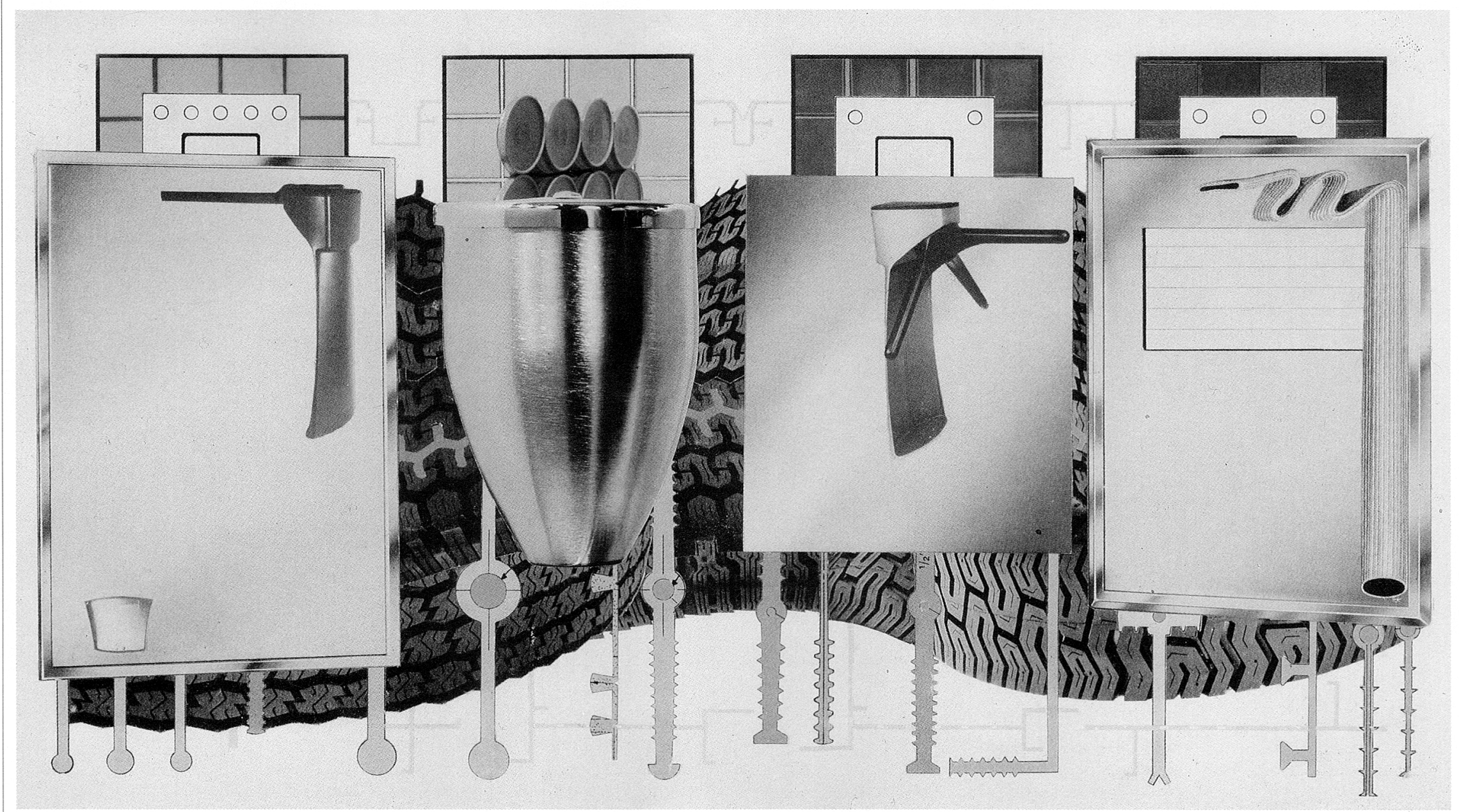




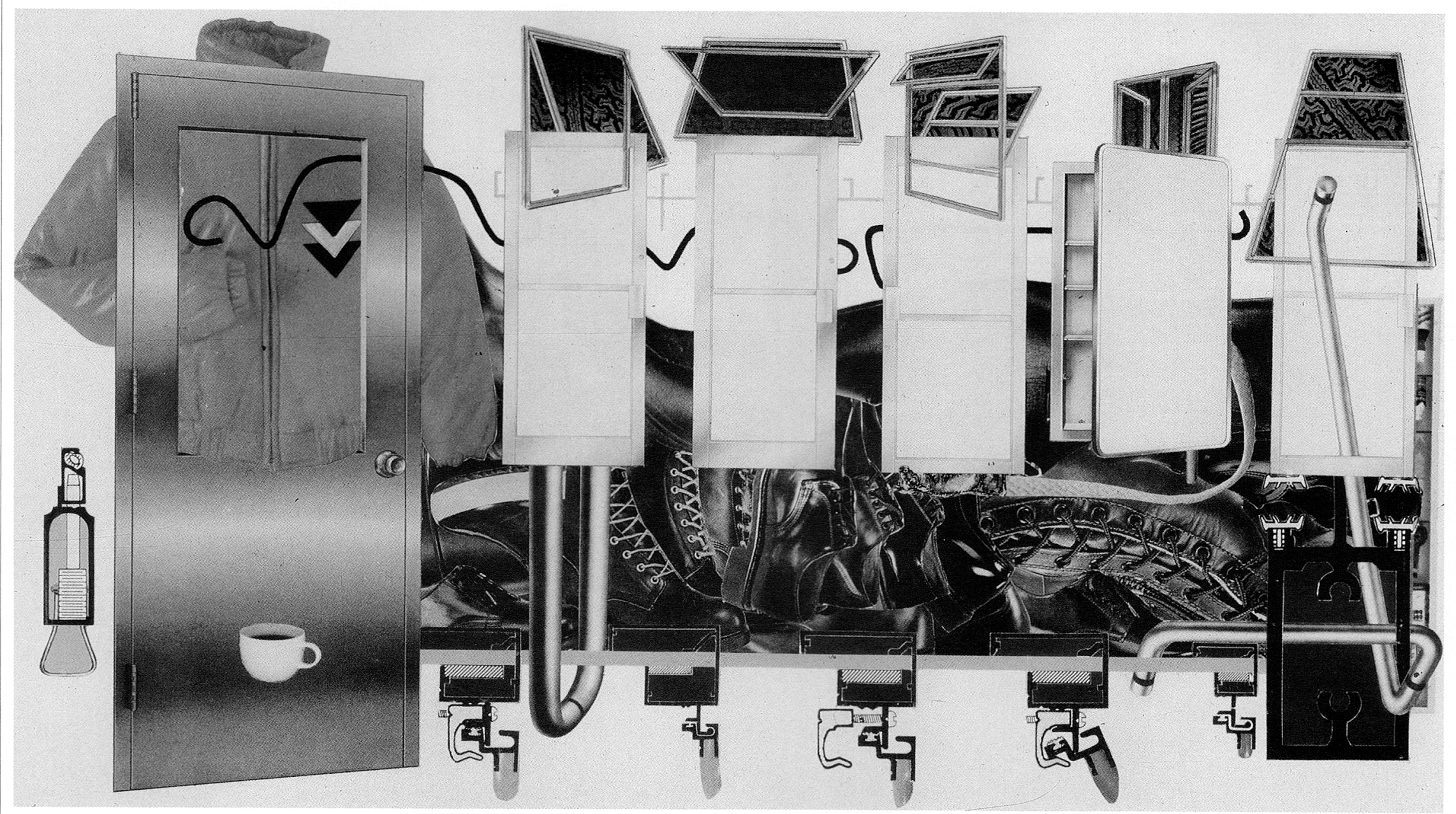

